\title{
34. ANISOTROPIC THERMAL CONDUCTIVITY OF PLEISTOCENE TURBIDITE SEDIMENTS OF THE NORTHERN JUAN DE FUCA RIDGE ${ }^{1}$
}

\author{
Earl E. Davis ${ }^{2}$ and David A. Seemann ${ }^{2}$
}

\begin{abstract}
Triaxial divided-bar thermal-conductivity measurements show the semilithified turbidite sediments at Ocean Drilling Program Sites 857 and 858 on the northern Juan de Fuca Ridge to be anisotropic, with the conductivity in the horizontal direction on average $25 \%$ higher than that in the vertical direction. Needle-probe measurements on unconsolidated sediment from the upper $3 \mathrm{~m}$ of an equivalent section nearby show a smaller but similar tendency. Scanning electron microscope images indicate that the anisotropy of the lithified sediment arises from the preferential alignment of flat mineral grains. The direction and inferred source of the thermal anisotropy are consistent with observations of other physical properties that are anisotropic, such as compressional and shear wave velocities and electrical capacitance. The observed dependence of thermal conductivity on porosity can be described mathematically with a simple geometric mean relationship using anisotropic grains mixed with seawater. The effective grain conductivities that provide the best fit to the data are $3.3 \mathrm{~W} / \mathrm{m}-\mathrm{K}$ for the horizontal direction and $2.6 \mathrm{~W} / \mathrm{m}-\mathrm{K}$ for the vertical. Within the range of shipboard calibration control, divided-bar conductivity measurements on isotropic igneous rocks, as well as conductivities of the sedimentary material measured with the divided bar in the horizontal direction (transverse to the core axes) agree with measurements made with a half-space needle probe aligned along the axes of split-core samples taken during Leg 139 . Above a conductivity of about $2 \mathrm{~W} / \mathrm{m}-\mathrm{K}$, however, the shipboard values are systematically low, suggesting that with rocks of high conductivity, additional calibration standards should be employed to reduce the errors arising from the analysis of the shipboard half-space results.
\end{abstract}

\section{INTRODUCTION}

Accurate estimates of thermal conductivity are required for determining heat flow from temperature measurements in the Earth and for extrapolating near-surface temperature data to estimate thermal regimes at greater depths. Several factors must be considered in estimating formation thermal conductivity from measurements obtained from core samples, including the effects of temperature on the conductivity of the rock matrix and pore fluid and the effects of removing the lithostatic overburden in the process of coring. These effects are discussed by Villinger et al. (this volume) and Davis and Wang (this volume). Another effect that should be considered, especially in sedimentary and foliated metamorphic rock formations, is anisotropy. Thermal-conductivity anisotropy can arise from several sources, including large- or small-scale bedding, preferential alignment of elongate or anisotropic detrital or authigenic mineral grains, and asymmetries of grain contacts and pore volumes.

The Pleistocene turbidite sediments sampled during Ocean Drilling Program (ODP) Leg 139, comprising siltstone and fine sandstone layers interbedded with silty claystone, have been found to possess a significant degree of seismic anisotropy at the scale represented by core specimens (Shipboard Scientific Party, 1992b). The measurements reported here document the degree to which these sediments are thermally anisotropic and the amount by which the shipboard measurements of thermal conductivity should be corrected when estimating the vertical component of thermal conductivity. The results can probably be extended to other locations where fine-grained turbidite sediments make up the dominant part of sedimentary sections.

${ }^{1}$ Mottl, M.J., Davis, E.E., Fisher, A.T., and Slack, J.F. (Eds.), 1994. Proc. ODP. Sci. Results, 139: College Station, TX (Ocean Drilling Program).

${ }^{2}$ Pacific Geoscience Centre, Geological Survey of Canada, P.O. Box 6000, Sidney, B.C., V8L 4B2, Canada.

\section{LABORATORY MEASUREMENTS}

\section{Divided-bar Measurements}

In this study, thermal conductivities of 32 semilithified sediment and 13 igneous-rock samples were measured on a divided-bar apparatus at the Pacific Geoscience Centre (PGC). The technique was first described by Lees (1892); the apparatus used for these measurements is similar to the one described by Beck $(1957 ; 1988)$. It consists of two constant-temperature baths at the top and bottom of a composite cylindrical "bar" comprising the sample bracketed symmetrically by a pair of copper measurement discs, a pair of standard discs, and a second pair of copper measurement discs. The baths maintained a $10^{\circ} \mathrm{C}$ temperature difference that was adjusted to evenly span the ambient laboratory temperature of typically $20^{\circ} \mathrm{C}$. The exterior surface of the composite bar was insulated to reduce radial heat loss and to ensure constant heat flow along the axis of the bar. After an equilibration period of 15-20 $\mathrm{min}$, the thermal resistance of the sample was determined simply by comparing the temperature drop across it to that across either the upper or lower standard disc. Comparison of the temperature drops across the two standards provided verification that radial heat loss was not a significant source of error.

The samples comprised cubes cut for shipboard physical properties measurements. The cubes were cut from split cores with a twinblade cut-off saw; hence the two pairs of opposing faces perpendicular to the split core face were generally quite parallel. The greatest nonparallelism (about $1^{\circ}$ ) occurred between the split face and its opposite side; the final cut was made with a single-blade saw. Imperfections were accommodated by the gimbaled mount of the upper part of the divided-bar apparatus. Most of the samples required some surface preparation before measurement to improve surface flatness and smoothness. The faces of the cubes were carefully wet-lapped on a glass plate using a series of carbide and aluminum silicate grinding compounds. Siltstone samples that were too fragile to undergo this process were dry-lapped using fine emery cloth. Final dimensions of the cubes ranged from 20 to $25 \mathrm{~mm}$. Samples with significant damage to edges or corners were not included in the measurements. In addition to the surface preparation, a viscous wetting agent was used on 
Table 1. Thermal-conductivity and porosity data for semilithified sediment samples from ODP Leg 139.

\begin{tabular}{|c|c|c|c|c|c|c|c|c|c|}
\hline \multirow[b]{2}{*}{$\begin{array}{l}\text { Core, section, } \\
\text { interval }(\mathrm{cm})\end{array}$} & \multirow[b]{2}{*}{ Lithology } & \multirow[b]{2}{*}{$\begin{array}{c}\text { Shipboard } \\
\text { porosity (\%) }\end{array}$} & \multicolumn{5}{|c|}{ Conductivity $(\mathrm{W} / \mathrm{m} \bullet \mathrm{K})$} & \multirow[b]{2}{*}{ Anisotropy } & \multirow[b]{2}{*}{$\begin{array}{l}\mathrm{Ka} / \mathrm{K} \\
(\mathrm{b}+\mathrm{c})\end{array}$} \\
\hline & & & Shipboard & $\begin{array}{l}\text { PGC } \\
\text { (a) }\end{array}$ & $\begin{array}{l}\text { PGC } \\
\text { (b) }\end{array}$ & $\begin{array}{c}\text { PGC } \\
\text { (c) }\end{array}$ & $(b+c)$ & & \\
\hline \multicolumn{10}{|l|}{$139-857 \mathrm{C}-$} \\
\hline $17 \mathrm{R}-2,46$ & Siltstone & & 1.69 & 1.47 & 1.54 & 1.56 & 1.55 & 0.05 & 0.95 \\
\hline $21 \mathrm{R}-1,51$ & Siltstone & & 1.73 & 1.70 & & 1.66 & & & \\
\hline $22 \mathrm{R}-1,56$ & Silty clay & 38.2 & 1.85 & 1.36 & 1.58 & 1.59 & 1.59 & 0.15 & 0.86 \\
\hline $22 \mathrm{R}-1,94$ & Siltstone & 38.2 & 1.70 & 1.50 & 1.89 & 1.96 & 1.93 & 0.25 & 0.78 \\
\hline $28 \mathrm{R}-1,97$ & Siltstone & 38.6 & 1.79 & 1.21 & 1.56 & 1.48 & 1.52 & 0.23 & 0.80 \\
\hline $29 \mathrm{R}-1,63$ & Siltstone & 38.6 & 1.68 & 1.60 & 1.89 & 1.53 & 1.71 & 0.07 & 0.94 \\
\hline $30 R-2,101$ & Silty clay & 38.2 & 1.67 & 1.29 & 1.82 & 1.72 & 1.77 & 0.31 & 0.73 \\
\hline $30 \mathrm{R}-3,31$ & Siltstone & 37.0 & 1.84 & 1.53 & 2.04 & 1.83 & 1.94 & 0.23 & 0.79 \\
\hline $31 \mathrm{R}-2,92$ & Silty clay & 41.3 & 1.57 & 1.46 & 1.85 & 1.87 & 1.86 & 0.24 & 0.78 \\
\hline $32 \mathrm{R}-2,47$ & Silty clay & 35.2 & & 1.42 & 1.92 & 1.79 & 1.86 & 0.27 & 0.77 \\
\hline $33 \mathrm{R}-2,76$ & Siltstone & 34.9 & & 1.77 & 2.25 & 1.99 & 2.12 & 0.18 & 0.83 \\
\hline $34 \mathrm{R}-1,92$ & Silty clay & 33.8 & 1.98 & 1.48 & 1.88 & 1.81 & 1.85 & 0.22 & 0.80 \\
\hline $36 \mathrm{R}-1,115$ & Siltstone & 33.1 & 2.01 & 1.59 & 1.93 & 1.85 & 1.89 & 0.17 & 0.84 \\
\hline $37 \mathrm{R}-3,4$ & Silty clay & 36.6 & & 1.35 & 1.99 & 2.18 & 2.09 & 0.43 & 0.65 \\
\hline $38 \mathrm{R}-1,80$ & Siltstone & 26.9 & 1.78 & 1.77 & 1.85 & & 1.85 & 0.04 & 0.96 \\
\hline $38 \mathrm{R}-2,101$ & Silty clay & 35.3 & $\begin{array}{l}1.69 \\
\end{array}$ & 1.36 & 1.86 & 2.02 & 1.94 & 0.35 & 0.70 \\
\hline $41 \mathrm{R}-2,90$ & Silty clay & 35.6 & 1.92 & 1.46 & 2.25 & 2.00 & 2.12 & 0.37 & 0.69 \\
\hline $44 \mathrm{R}-1,45$ & Siltstone & 32.6 & 2.06 & 1.42 & 1.91 & 1.91 & 1.91 & 0.29 & 0.74 \\
\hline $47 \mathrm{R}-1,25$ & Siltstone & 31.7 & 2.07 & 1.58 & 2.14 & 1.90 & 2.02 & 0.24 & 0.78 \\
\hline $47 \mathrm{R}-2,14$ & Silty clay & 29.4 & 1.77 & 1.46 & 2.13 & 2.26 & 2.20 & 0.40 & 0.67 \\
\hline $49 \mathrm{R}-1,82$ & Silty clay & 28.8 & 2.00 & 1.49 & 2.13 & 1.59 & 1.86 & 0.22 & 0.80 \\
\hline $49 \mathrm{R}-1,127$ & Silty clay & 30.2 & 1.92 & 1.61 & 2.11 & 1.99 & 2.05 & 0.24 & 0.79 \\
\hline $49 \mathrm{R}-2,3$ & Siltstone & 30.5 & 1.93 & 1.71 & 2.08 & 2.01 & 2.05 & 0.18 & 0.84 \\
\hline $49 \mathrm{R}-2,49$ & Sandstone & 26.5 & 2.03 & 1.91 & $\begin{array}{l}2.00 \\
1.79\end{array}$ & 1.78 & 1.79 & -0.07 & 1.07 \\
\hline $50 \mathrm{R}-1,125$ & Silty clay & 29.9 & 1.92 & 1.48 & 2.17 & 2.11 & 2.14 & 0.36 & 0.69 \\
\hline $51 \mathrm{R}-1,32$ & Silty clay & 34.1 & 2.05 & 1.43 & 2.14 & 2.02 & 2.08 & 0.37 & 0.69 \\
\hline \multicolumn{10}{|l|}{ 139-857D- } \\
\hline $12 \mathrm{R}-1,32$ & Siltstone & 20.8 & 2.11 & 2.15 & 2.58 & 2.48 & 2.53 & 0.16 & 0.85 \\
\hline $16 \mathrm{R}-1,76$ & Siltstone & 15.2 & 2.23 & 2.26 & 2.82 & 2.46 & 2.64 & 0.16 & 0.86 \\
\hline $17 \mathrm{R}-1,69$ & Siltstone & 13.7 & 1.72 & 1.98 & 2.49 & 2.22 & 2.36 & 0.17 & 0.84 \\
\hline $28 \mathrm{R}-1,34$ & Bedded siltstone & 7.4 & 2.59 & 2.99 & 2.79 & 3.29 & 3.04 & 0.02 & 0.98 \\
\hline $31 \mathrm{R}-1,28$ & Siltstone & 14.2 & 2.46 & 2.47 & 2.97 & 3.06 & 3.02 & 0.20 & 0.82 \\
\hline \multicolumn{10}{|l|}{$139-858 \mathrm{~A}-$} \\
\hline & Siltstone & 40.1 & 1.99 & 1.55 & 1.98 & 2.10 & 2.04 & 0.27 & 0.76 \\
\hline
\end{tabular}

NOTE: Anisotropy is computed as the difference between the horixontal and vertical components divided by the average. Axes designations follow those given in Shipboard Scientific Party (1992a): $a=c o r e$ (vertical) axis; $b=$ direction perpendicular to split-core face (horizontal); $c=$ direction across split-core face (horizontal). PGC $=$ Pacific Geoscience Centre.

the cube faces as a final step to reduce the errors caused by thermal contact resistance.

All samples had been oven-dried for shipboard porosity determinations and required resaturation for the conductivity measurements. Following the surface preparation, the samples were placed in a vacuum chamber evacuated to $0.15 \mathrm{~atm}$ for approximately $4 \mathrm{hr}$. They were immersed in water while still under vacuum, then allowed to soak overnight at $1 \mathrm{~atm}$. To minimize evaporation during measurements, the cubes were wrapped in thin plastic sheeting before being insulated with a plastic foam jacket. Measurements along the three axes of each sample were not done consecutively. Instead, the cubes were reimmersed in water after each measurement to reduce the possibility of progressive drying.

The dimensions of all samples were determined with a dial caliper. Thicknesses were used to compute conductivities from measured thermal resistances. Cross-sectional areas were used to determine the concentration of heat flowing through the cubes between the circular divided-bar faces. Normally, core samples are cut into cylindrical discs that closely match the $3.6-\mathrm{cm}$ diameter of the divided-bar components, and little or no correction for mismatched areas is required. In the present case, however, the ratio of the cross-sectional areas of the bar and the cubes was substantial (typically between 1.8 and 2.3). Corrections for the mismatch were made assuming that all of the heat between the copper faces flows through the sample. A simple test was conducted to verify that no systematic errors were introduced through this assumption by measuring the conductivity of 2-cm-square subsamples cut from previously measured 3.6 -cm-diameter discs of crystalline rock. Conductivities of the seven samples used for the test ranged from 1.6 to $3.8 \mathrm{~W} / \mathrm{m}-\mathrm{K}$. Measurements made on the discs and cubes of individual samples agreed to within $10 \%$ on a sample by sample basis, and there was no systematic difference on average (less than $1 \%$ ). Measurement reproducibility of these test samples as well as of the sediment cubes was also typically $10 \%$.

\section{Needle-probe Measurements}

Conductivity measurements were also made on unconsolidated sediment collected during a cruise in 1992 with a 10-cm-diameter gravity corer from Cascadia Basin, roughly $100 \mathrm{~km}$ east of Middle Valley but in the same turbidite sediment province. These measurements were made with a needle-probe apparatus using a pulsed heat source (described in Lewis et al., in press). Two measurements were made at each of several depths in two cores. The first measurement was made with the needle inserted through the core liner and aligned across the core. The core was then cut transversely, and a second measurement was made with the needle oriented along the axis of the core. Repeat measurements made at a few selected depths agreed to better than $3 \%$.

\section{RESULTS}

Thermal conductivities of the sedimentary rocks and several selected igneous rocks are compiled in Tables 1 and 2, along with shipboard porosities measured on the cubes, and shipboard thermal conductivities measured on split-core sections. The latter were made within a few centimeters (all less than $10 \mathrm{~cm}$ ) of where the cube samples were cut. Most values measured on individual cubes along the $b$ and $\mathrm{c}$ axes differ by less than $10 \%$, and in the following discussion, the horizontal component of conductivity is taken as the average of the 
Table 2. Thermal-conductivity and porosity data for igneous rocks from Leg 139.

\begin{tabular}{|c|c|c|c|c|c|c|c|c|}
\hline \multirow[b]{2}{*}{$\begin{array}{l}\text { Core, section, } \\
\text { interval }(\mathrm{cm})\end{array}$} & \multirow[b]{2}{*}{ Lithology } & \multirow[b]{2}{*}{$\begin{array}{c}\text { Shipboard } \\
\text { porosity (\%) }\end{array}$} & \multicolumn{4}{|c|}{ Conductivity $(\mathrm{W} / \mathrm{m} \cdot \mathrm{K})$} & \multirow[b]{2}{*}{ Anisotropy } & \multirow[b]{2}{*}{$\begin{array}{l}\mathrm{Ka} / \mathrm{K} \\
(\mathrm{b}+\mathrm{c})\end{array}$} \\
\hline & & & Shipboard & $\begin{array}{c}\text { PGC } \\
\text { (a) }\end{array}$ & $\begin{array}{l}\text { PGC } \\
(b+c)\end{array}$ & $\begin{array}{c}\text { PGC } \\
(a+b+c)\end{array}$ & & \\
\hline \multicolumn{9}{|l|}{ 139-857C- } \\
\hline $60 \mathrm{R}-1,18$ & Diabase & 6.8 & 2.00 & 2.54 & 2.63 & 2.35 & 0.04 & 0.97 \\
\hline $61 \mathrm{R}-1,69$ & Diabase & 8.5 & 1.95 & 2.09 & 2.10 & 2.10 & 0.00 & 1.00 \\
\hline $63 \mathrm{R}-1,57$ & Diabase & 8.7 & 1.64 & 2.27 & 2.23 & 2.24 & 0.02 & 1.02 \\
\hline $64 \mathrm{R}-2,39$ & Diabase & 12.4 & 2.21 & 2.26 & 2.16 & 2.19 & 0.05 & 1.05 \\
\hline $66 \mathrm{R}-1,39$ & Altered basalt & 20.6 & 1.95 & 2.13 & 2.12 & 2.12 & 0.00 & 1.00 \\
\hline $68 \mathrm{R}-3,24$ & Diabase & 10.3 & 1.70 & 2.08 & 2.14 & 2.12 & 0.03 & 0.97 \\
\hline \multicolumn{9}{|l|}{ 139-187D- } \\
\hline $14 \mathrm{R}-1,19$ & Diabase & 14.8 & & 2.39 & 2.14 & 2.22 & 0.11 & 1.12 \\
\hline $18 \mathrm{R}-1,60$ & Diabase & 5.6 & 2.15 & 2.50 & 2.18 & 2.29 & 0.14 & 1.15 \\
\hline $36 \mathrm{R}-1,83$ & Altered diabase & 3.5 & 1.96 & 2.54 & 2.63 & 2.60 & 0.03 & 0.97 \\
\hline \multicolumn{9}{|l|}{ 139-858G- } \\
\hline 1R-1, 13 & Basalt & & & 2.11 & 2.08 & 2.09 & 0.01 & 1.01 \\
\hline $2 \mathrm{R}-1,35$ & Basalt & & & 1.93 & 1.96 & 1.95 & 0.02 & 0.98 \\
\hline $7 \mathrm{R}-1,41$ & Basalt & & & 1.94 & 2.09 & 1.97 & 0.08 & 0.93 \\
\hline $16 \mathrm{R}-1,63$ & Diabase & & & 2.04 & 1.90 & 1.95 & -0.07 & 1.07 \\
\hline
\end{tabular}

$\mathrm{b}$ and $\mathrm{c}$ axis values. All shipboard conductivity measurements included in Tables 1 and 2 were made using a half-space transient line-source technique (Vacquier, 1985), with the source aligned along the axis of the core (Shipboard Scientific Party, 1992a). These measurements are taken to be representative of the combined b- and c-axis components.

Needle-probe measurements made on shallow gravity cores from the ridge-flank area are included in Table 3. As in the case of the shipboard half-space line-source measurements, the horizontal component of conductivity is given as the value measured with the needle aligned along the axis of the core. The vertical-component conductivity is derived from the values obtained from both cross- and alongcore needle orientations, assuming that the nature of the anisotropy is elliptical, and using the relationship

$$
K_{a}=\mathrm{K}_{a+b}{ }^{2} / \mathrm{K}_{b+c} .
$$

\section{Thermal Conductivity Anisotropy}

A systematic difference between the horizontal- and verticalcomponent conductivities of the sedimentary rocks (Table 1) is seen clearly in Figure 1, where both igneous and sedimentary rocks are included in a plot of vertical- vs. horizontal-component conductivity. The igneous rocks display virtually no anisotropy; values along different axes of most individual samples agree to within a few percent. In contrast, nearly all data for the semilithified sedimentary samples exhibit higher horizontal conductivity. Of those samples that display little or no anisotropy, one is coarse grained (139-857C-49R-2, 49 $\mathrm{cm}$ ), and another (139-857D-28R-1, $34 \mathrm{~cm}$, excluded from Figs. 1 and 2) has a large dip that causes the bedding plane to intersect the a, $\mathrm{b}$, and $\mathrm{c}$ axes at nearly equal angles. There is a slight tendency for the soft-sediment sample measurements to be biased as well, indicating that anisotropy may be present at the full range of conductivities represented by the data. For the lithified samples, the horizontal values are on average about $25 \%$ greater than the vertical values. Anisotropy of about the same magnitude is also present in other physical properties, including compressional-wave velocity (Shipboard Scientific Party, 1992b), shear-wave velocity, and electrical capacitance (R. Knight, pers. comm., 1992).

\section{Conductivity vs. Porosity}

Because of the relatively large contrast in conductivity between the sediment grains (which range from roughly 2 to $7 \mathrm{~W} / \mathrm{m}-\mathrm{K}$ ) and seawater (about $0.6 \mathrm{~W} / \mathrm{m}-\mathrm{K}$ ), the conductivity of sediment of a given
Table 3. Thermal-conductivity and porosity data for uncolidated sediments sampled with a gravity corer from the eastern flank of the Juan de Fuca Ridge at $47^{\circ} 43^{\prime} \mathrm{N}, 127^{\circ} 47^{\prime} \mathrm{W}$.

\begin{tabular}{|c|c|c|c|c|c|}
\hline \multirow[b]{2}{*}{ Core } & \multirow{2}{*}{$\begin{array}{l}\text { Depth } \\
(\mathrm{cm})\end{array}$} & \multirow{2}{*}{$\begin{array}{c}\text { Porosity } \\
\text { (\%) }\end{array}$} & \multicolumn{2}{|c|}{$\begin{array}{l}\text { Needle probe } \\
\text { conductivity } \\
(\mathrm{W} / \mathrm{m} \cdot \mathrm{K})\end{array}$} & \multirow{2}{*}{$\begin{array}{c}\text { Estimated } \\
\text { conductivity } \\
\text { (W/m-K) } \\
\text { (a) }\end{array}$} \\
\hline & & & $(a+b)$ & $(b+c)$ & \\
\hline 21 & 65 & 83.1 & 0.69 & 0.77 & 0.61 \\
\hline 21 & 80 & 83.3 & 0.77 & 0.82 & 0.72 \\
\hline 21 & 95 & 80.6 & 0.81 & 0.79 & 0.83 \\
\hline 21 & 145 & 79.1 & 0.82 & 0.86 & 0.78 \\
\hline 21 & 160 & 78.1 & 0.87 & 0.85 & 0.89 \\
\hline 21 & 175 & 78.6 & 0.84 & 0.82 & 0.86 \\
\hline 21 & 225 & 65.8 & 1.11 & 0.93 & 1.32 \\
\hline 21 & 240 & 70.4 & 1.10 & 0.88 & 1.37 \\
\hline 21 & 255 & 76.8 & 0.85 & 0.93 & 0.78 \\
\hline 44 & 125 & 84.1 & 0.77 & 0.78 & 0.76 \\
\hline 44 & 135 & 84.0 & 0.77 & 0.76 & 0.78 \\
\hline 44 & 145 & 84.7 & 0.77 & 0.76 & 0.78 \\
\hline 44 & 204 & 79.7 & 0.84 & 0.85 & 0.83 \\
\hline 44 & 215 & 79.6 & 0.83 & 0.80 & 0.86 \\
\hline 44 & 225 & 78.3 & 0.86 & 0.86 & 0.86 \\
\hline 44 & 320 & 74.0 & 0.84 & 0.85 & 0.83 \\
\hline 44 & 340 & 81.2 & 0.85 & 0.87 & 0.83 \\
\hline 44 & 454 & 54.1 & 1.10 & 1.40 & 0.86 \\
\hline 44 & 474 & 78.4 & 0.86 & 0.87 & 0.85 \\
\hline 44 & 494 & 76.2 & 0.90 & 0.98 & 0.83 \\
\hline
\end{tabular}

NOTE: Conventions as in Table 4. Measurements made with the needle inserted across core samples are designated $(\mathrm{a}+\mathrm{b})$, and those made with the needle aligned along the core axis are designated $(b+c)$.

lithology is dependent primarily on porosity. A simple relationship between conductivity and porosity that is empirically well justified and often used is of the form

$$
K=K_{w}{ }^{P} \times K_{g}{ }^{l-P},
$$

where $K_{g}$ is the geometric average conductivity of the constituent mineral grains, $K_{w}$ is the conductivity of seawater, and $P$ is porosity (e.g., Woodside and Messmer, 1961; Brigaud and Vasseur, 1989). This relationship is used in Figure 2, where the observed vertical and horizontal components of conductivity are plotted against porosity 


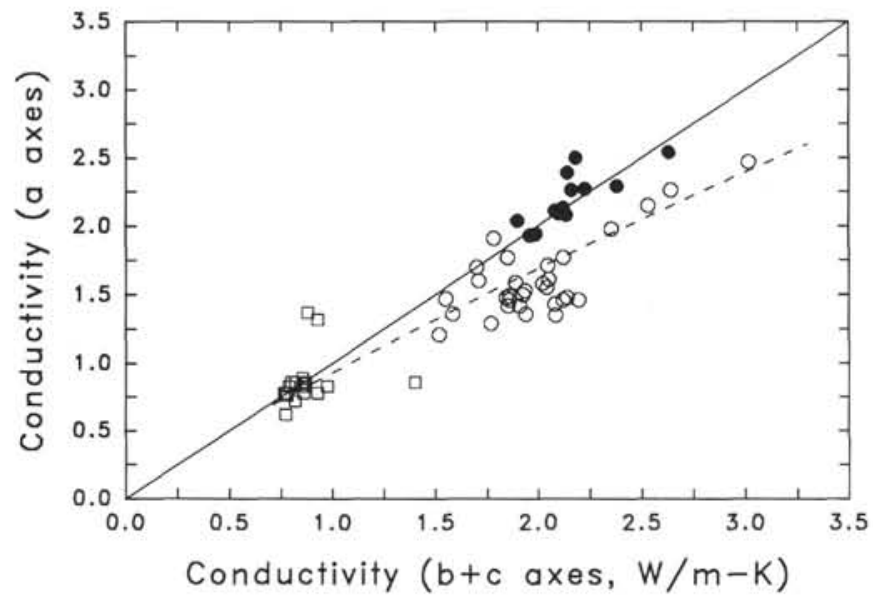

Figure 1. Ratio of horizontal to vertical components of thermal conductivity shown as a plot of measurements made along (a axis) vs. transverse to (the average of $b$ and $c$ axes) core axes. Data are from unconsolidated sediment collected on the eastern flank of the Juan de Fuca Ridge (squares; Table 3), and from semilithified sediments (open circles; Table 1) and igneous rocks (filled circles; Table 2) collected at Sites 857 and 858 . The dashed line is discussed in the text.

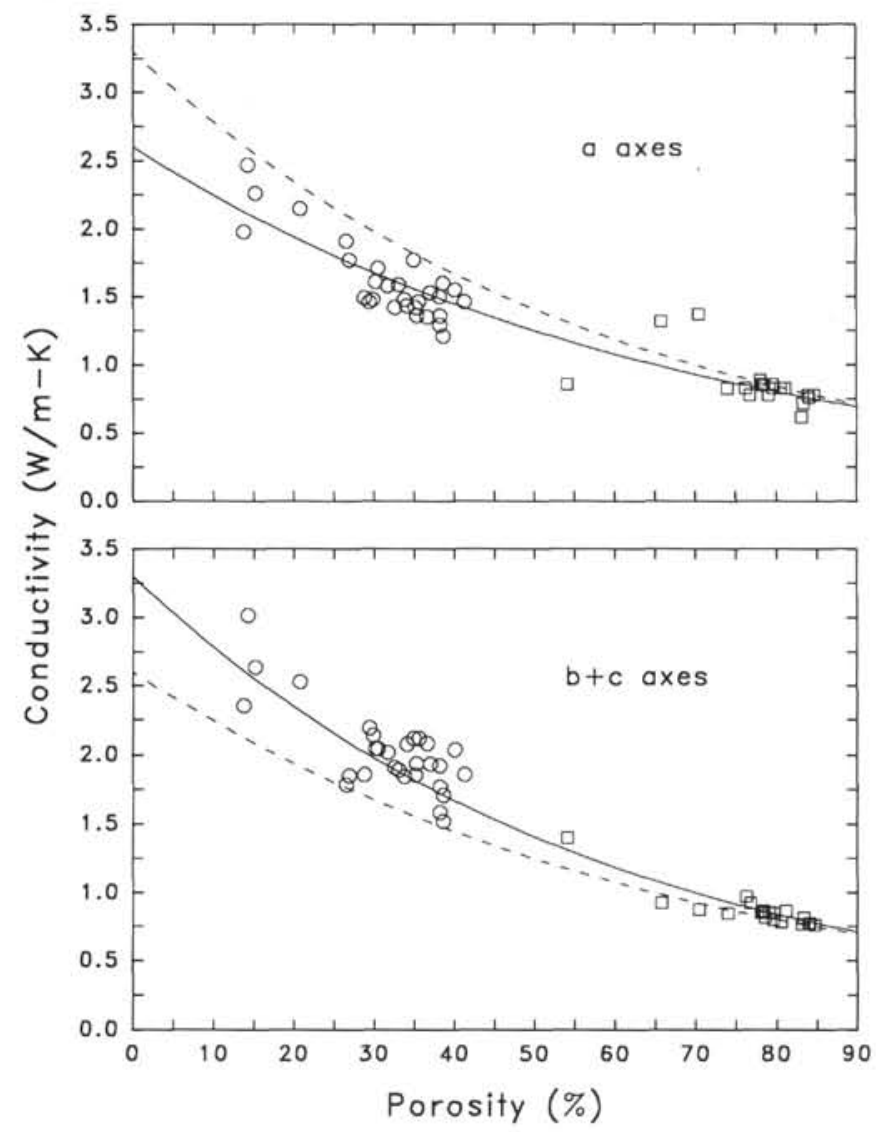

Figure 2. Thermal conductivity, measured in directions parallel to (a axis) and perpendicular to (the average of b-and c-axes measurements) the vertical axes of cores, plotted against porosity. Predictions of a simple geometric mean relationship are shown assuming average mineral conductivities of $2.6 \mathrm{~W} / \mathrm{m}-\mathrm{K}$ (solid line in a axis plot) and $3.3 \mathrm{~W} / \mathrm{m}-\mathrm{K}$ (solid line in $\mathrm{b}+\mathrm{c}$ axes plot) for the vertical and horizontal directions, respectively. Circles show measurements made on cubes cut from cores from Holes $857 \mathrm{C}, 857 \mathrm{D}$, and $858 \mathrm{~A}$ (Table 1); squares show measurements made on gravity cores from an area near Middle Valley (Table 2). and compared to curves predicted by the geometric mean relationship using average grain conductivities of 2.6 and $3.3 \mathrm{~W} / \mathrm{m}-\mathrm{K}$ for the vertical and horizontal components, respectively. The generally good fit of the curves to the data suggests that the conductivity anisotropy can be accounted for by a simple (geometric mean) mixture of water and anisotropic sediment grains. The result of this mathematical mixture is also shown in Figure 1, where the horizontal and vertical conductivities, predicted for the geometric mean mixtures of oriented anisotropic sediment grains with water, are plotted against one another (dashed line).

\section{Microscopic Structure}

In most cases, the cause of the thermal-conductivity anisotropy is not physically evident by casual inspection of the samples. A few of the samples possess bedding down to a scale of about $1 \mathrm{~mm}$, although most are macroscopically homogeneous. Scanning electron microscope images of the finer-grained samples, however, show pronounced "layering" caused by a subhorizontal alignment of flat grains, presumably mica and clay minerals. This microscopic structure is illustrated clearly in Figure 3, where two faces of a sample, one cleaved transverse to the core axis and one parallel to the core axis, are shown at two levels of magnification. The transverse face is relatively smooth compared to the near-vertical face that cuts the bedding. The surface of the former appears to be made up of overlapping plates, whereas the latter appears to reveal the edges of similar plates in outcrop. The inferred "bedding" direction in this sample is very close to perpendicular to the core axis and is aligned horizontally in Figure 3.

This structure suggests that the observed conductivity anisotropy is caused by some combination of grain shape and grain anisotropy. Preferential alignment of flat or elongate, but thermally isotropic, mineral grains would give rise to significant anisotropy as a result of the more efficient thermal paths created in the direction of alignment. In the zero-porosity limit, however, this anisotropy would disappear. Studies of low-porosity rocks (Clark, 1966) and results from the lowest porosity samples included here (Figs. 1 and 2) suggest that the intrinsic anisotropy of some of the aligned minerals contributes as well. Mica is the most likely source. Measurements on muscovite reported by Clark (1966) suggest a very high degree of anisotropy, with the conductivity in the direction of the $\mathrm{C}$ crystal axis being more than a factor of 5 lower than that in the A and B axes directions. Preferential orientation of other anisotropic minerals such as quartz would have the same effect.

Clearly, models more sophisticated than the anisotropic grain geometric mean relationship could be developed that would be physically more meaningful and would account for the various effects of grain shape and orientation, grain contacts, and other complexities. However, it is unlikely that the data presented here could be used to discriminate such a model from the simple one given. To do this, more data are needed from low-porosity samples to test whether the anisotropy diminishes toward the zero-porosity limit, as it would if the anisotropy were caused solely by the alignment of flat grains, or whether it continues to increase as suggested by the simple anisotropic grain model.

\section{Shipboard vs. Laboratory Results}

A plot of shipboard-measured conductivity vs. porosity similar to those shown in Figure 2 was presented by the Shipboard Scientific Party (1992b). To provide a best-fit geometric mean mixing relationship to those data required a grain conductivity of $3.12 \mathrm{~W} / \mathrm{m}-\mathrm{K}$, slightly less than the value suggested for the horizontal-component data in Figure 2. Because the shipboard measurements were made with a needle aligned along the axis of the core, and thus represent the horizontal component of conductivity, the results derived from the shipboard data and the PGC (divided-bar) b- and c-axes data should agree. Some scatter is expected because not all shipboard needleprobe measurements are exactly coincident with the intervals from 


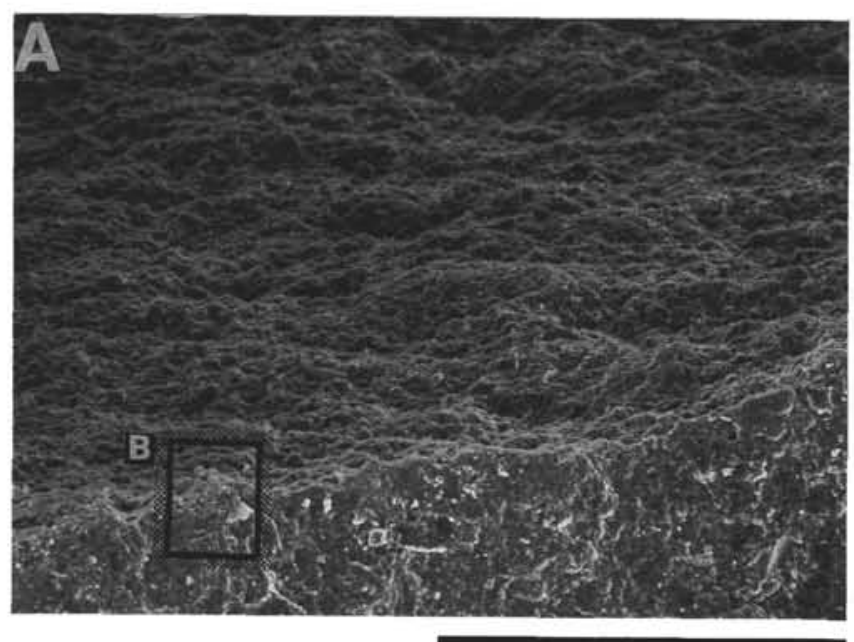

$500 \mu \mathrm{m}$

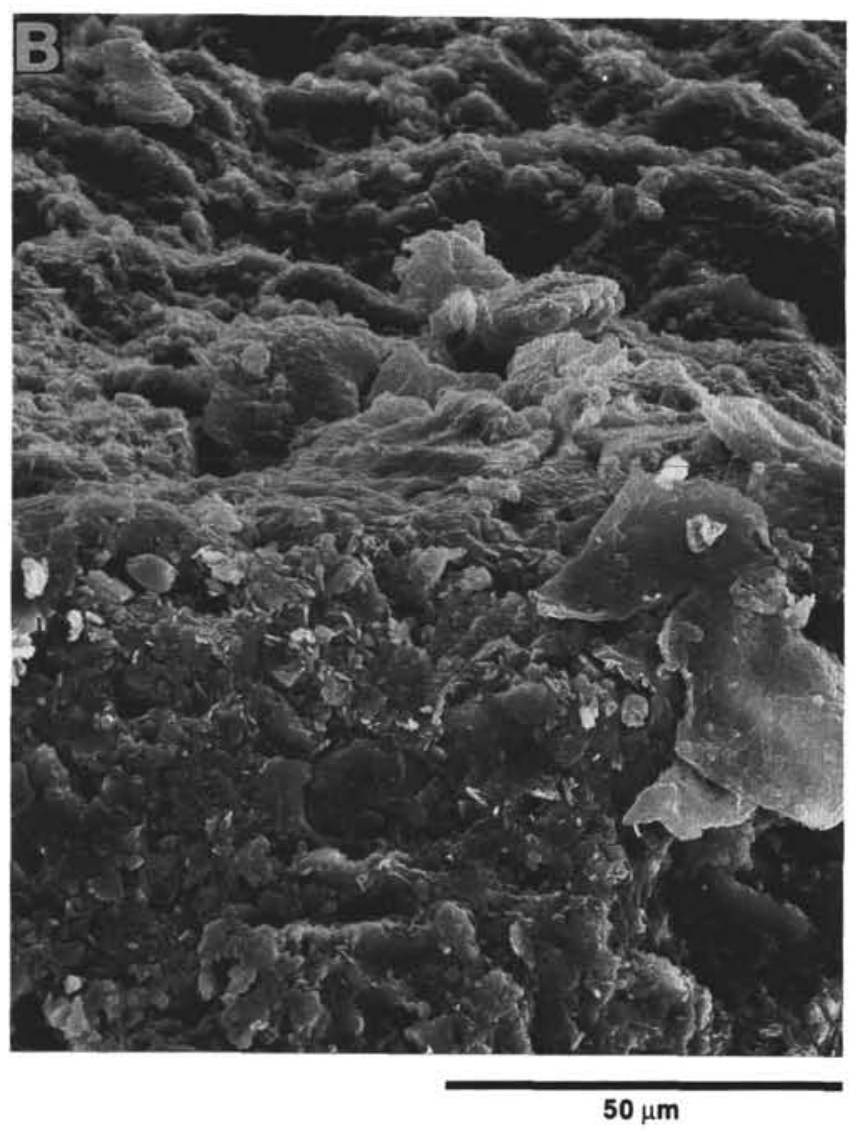

Figure 3. Scanning electron microscope image of sediment Sample 139-857C41R-2, 89-91 cm, one at lower (A) and one at higher magnification (B). Two faces are seen in both fields of view, one cleaved transverse to (lower parts of images) and one parallel to the core axis (upper parts of images). The approximate field of view of B is outlined on A.

which the cubes were cut. The systematic difference in computed grain conductivity ( $3.3 \mathrm{vs}$. $3.12 \mathrm{~W} / \mathrm{m}-\mathrm{K})$ cannot be accounted for by this source of random error, however, and we suspect that there may be a systematic error in one of the data sets.

The difference is more clearly revealed through the direct comparison of the two data sets shown in Figure 4. At lower conductivities

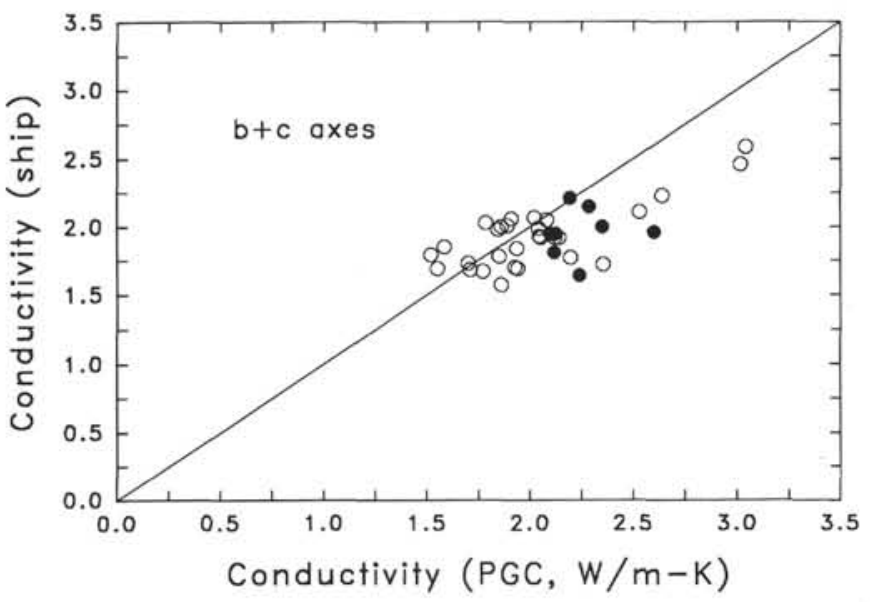

Figure 4. A comparison of the thermal conductivities of sediments (open circles) and igneous rocks (filled circles) from Sites 857 and 858 measured onboard during Leg 139 with a needle imbedded in an epoxy block and measured in the laboratory at the Pacific Geoscience Centre with a divided bar apparatus.

the independent measurements agree to within about $10 \%$, but above a conductivity of about $2.0 \mathrm{~W} / \mathrm{m}-\mathrm{K}$, a systematic bias emerges, with the PGC measurements systematically higher than the shipboard measurements. The discrepancy continues to increase at the much higher conductivities that characterize massive sulfide rocks sampled at Site 856 , with divided-bar measurements being nearly twice the shipboard values (Gröschel-Becker et al., this volume).

The greatest source of systematic error in the divided-bar conductivity measurements is probably caused by the mismatch in the size of the samples $(3.0-3.5 \mathrm{~cm}$ diagonally across the square faces) and the size of the bar ( $3.6 \mathrm{~cm}$ diameter). As described previously, however, this source of error was tested and found to be small, and thus cannot account for the discrepancy in the measurements.

It is more likely that the disagreement between the PGC dividedbar and shipboard measurements is caused by error in the shipboard measurements. These "half-space" measurements, made with a needle imbedded in an epoxy block (Vacquier, 1985), were analyzed in a manner identical to a standard constant-heat-source needle-probe method (Von Herzen and Maxwell, 1959). "Absolute" values of conductivity, calculated from the slope of the temperature rise vs. logarithmic time, were then adjusted with a linear correction factor that was determined empirically by comparing the absolute measurements with known values of three calibration standards (Shipboard Scientific Party, 1992a). The conductivities of these standards, $0.96,1.61$, and $2.05 \mathrm{~W} / \mathrm{m}-\mathrm{K}$, span the range over which the PGC divided-bar and the shipboard halfspace measurements generally agree. Unfortunately, the simple correction for the half-space appears to break down outside this range, probably for several reasons. One is that the characteristics of the system become nonlinear if the contrast between the conductivity of the sample and that of the material in which the line heat source is imbedded becomes large, and the theory for cylindrical geometry cannot be applied. Another reason is that the heat conducted from the line source will reach the sample boundaries within the measurement time in the case of high conductivity samples. This will cause computed values of conductivity to be erroneously low. Additional shipboard calibration standards and a careful examination of these problems are clearly needed before the results of shipboard measurements on high-conductivity rocks can be accepted with confidence.

\section{SUMMARY AND CONCLUSIONS}

The thermal conductivity of semilithified turbidites sampled during Leg 139 is highly anisotropic. Values measured with a divided-bar apparatus in the vertical direction are on average roughly $25 \%$ lower than those measured in the horizontal direction. Values measured 
during the drilling leg on split cores with a needle probe imbedded in a half space represent the latter direction, whereas the former is appropriate for computing and constraining models for vertical heat transport. Thus, the effect of anisotropy must be considered carefully in applying shipboard conductivity measurements to thermal problems in this and similar sedimentary environments. The anisotropy in thermal conductivity, and probably the anisotropy observed in other physical properties, appears to arise from the preferential horizontal orientation of flat and anisotropic minerals. It is most significant in fine-grained material. The relationship between porosity and conductivity for the horizontal and vertical components of conductivity appear individually to be well matched by simple geometric mean mixing relationships. The effective grain conductivity appropriate for the horizontal component is $3.3 \mathrm{~W} / \mathrm{m}-\mathrm{K}$, and for the vertical, 2.6 $\mathrm{W} / \mathrm{m}-\mathrm{K}$. The latter value, rather than the former or the shipboard estimate, should be used in schemes of estimating bulk thermal conductivity from porosity or seismic velocity.

Shipboard half-space results agree with the divided-bar measurements over a range of conductivity up to about $2 \mathrm{~W} / \mathrm{m}-\mathrm{K}$. At higher conductivities, outside the range of shipboard calibration standards, shipboard measurements are progressively lower systematically than the divided-bar measurements. Additional calibration standards are clearly needed for high conductivity samples.

\section{ACKNOWLEDGMENTS}

The authors gratefully acknowledge W. Bentkowski for her assistance with the needle-probe measurements, and M. Johns for making the SEM images in Figure 3. The divided-bar apparatus was kindly provided by T. Lewis. GSC Contribution 10293.

\section{REFERENCES}

Beck, A.E., 1957. A steady state method for the rapid measurement of the thermal conductivity of rocks. J. Sci. Instr., 34:185-189.
1988. Methods for determining thermal conductivity and thermal diffusivity. In Haenel, R., Rybach, L., and Stegena, L. (Eds.) Handbook of Terrestrial Heat-Flow Density Determination: Dordrecht (Kluwer Academic Publishers), 87-124.

Brigaud, F., and Vasseur, G., 1989. Mineralogy, porosity and fluid control on thermal conductivity of sedimentary rocks. Geophys. J., 98:525-542.

Clark, S.P., 1966. Thermal conductivity. In Clark, S.P. (Ed.), Handbook of Physical Constants. Mem.-Geol. Soc. Am., 97:461-482.

Lees, C.H., 1892. On the thermal conductivities of crystals and other bad conductors. Philos. Trans. R. Soc. London A, 183:491-509.

Lewis, T.J., Villinger, H., and Davis, E.E., in press. Thermal conductivity measurements of rock fragments using a pulsed needle probe. Can. J. Earth Sci.

Shipboard Scientific Party, 1992a. Explanatory notes. In Davis, E.E., Mottl, M.J., Fisher, A.T., et al., Proc. ODP, Init. Repts., 139: College Station, TX (Ocean Drilling Program), 55-97.

1992b. Site 857. In Davis, E.E., Mottl, M.J., Fisher, A.T., et al., Proc. ODP, Init. Repts., 139: College Station, TX (Ocean Drilling Program), 283-429.

Vacquier, V., 1985. The measurement of thermal conductivity of solids with a transient linear heat source on the plane surface of a poorly conducting body. Earth Planet. Sci. Lett., 74:275-279.

Von Herzen, R.P., and Maxwell, A.E., 1959. The measurement of thermal conductivity of deep-sea sediments by a needle-probe method. J. Geophys. Res., 64:1557-1563.

Woodside, W., and Messmer, J.H., 1961. Thermal conductivity of porous media in unconsolidated sands. J. Appl. Phys., 32:1688-1699.

\footnotetext{
Abbreviations for names of organizations and publications in ODP reference lists follow the style given in Chemical Abstracts Service Source Index (published by American Chemical Society).
}

Date of initial receipt: 4 January 1993

Date of acceptance: 28 April 1993

Ms 139SR-245 